\title{
Cutis MarmorataTelangectásica Congénita
}

\section{Cutis Marmorata Telangiectatica Congenita}

\section{Perla Esmeralda Rubí Rodas* Héctor Rubén Caballero Castro **}

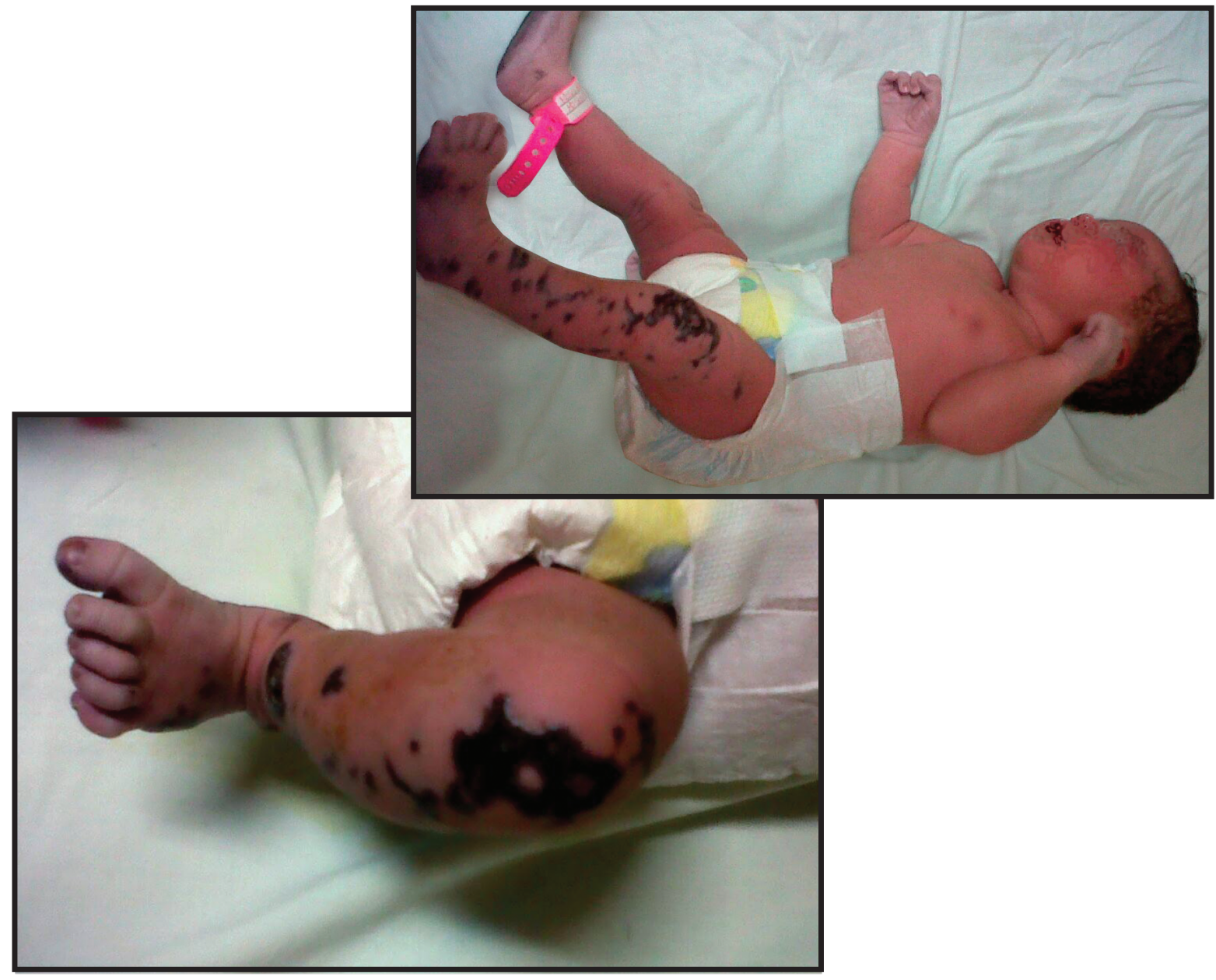

Recién nacido de término, femenino que presenta en el miembro inferior izquierdo máculas eritematosas violáceas de aspecto reticulado que no desaparecen con la digito- presión, de bordes irregulares, piel atrófica y telangiectasias. Estas lesiones son características de una malformación vascular cutánea que compromete a vasos capilares y venosos Ilamada Cutis Marmorata Telangiectásica Congénita (CMTC).

* Médico Residente de primer año de Pediatría de la Universidad Nacional Autónoma en el Valle de Sula UNAH-VS

** Dermatólogo pediatra del Instituto Hondureño de Seguridad Social-Hospital Regional del Norte IHSS-HRN

Dirigir correspondencia a: rubi_perla27@hotmail.com

Recibido: 24 de Febrero 2015, Aprobado: 2 de Marzo 2,015
No se conoce la causa pero afecta 1/3,000 recién nacidos, predominantemente a niñas y mejora durante la infancia, ya que las lesiones resuelven espontáneamente, aunque en un $15 \%$ persisten lesiones hasta la edad adulta. Su distribución es segmentaria y asimétrica. Los sitios afectados son principalmente las extremidades inferiores y brazos. La CMTC está asociada a macrocefalia, glaucoma congénito, sindactilia, hipoplasia renal y el síndrome de Kartagener. El diagnóstico es clínico ya que el estudio histológico es inespecífico. El pronóstico es generalmente bueno, aunque depende de anomalías asociadas. 